\title{
Pesticide residues in raspberries from the south-eastern Poland in 2009-2012
}

\author{
Pozostałości środków ochrony roślin w malinach pochodzących \\ z Polski południowo-wschodniej w latach 2009-2012
}

\author{
Aneta Matyaszek, Ewa Szpyrka, Magdalena Podbielska, \\ Magdalena Słowik-Borowiec, Anna Kurdziel, Julian Rupar
}

\begin{abstract}
Summary
Raspberries belong to a broad group of berry plants. The cultivation of raspberries is an important, rapidly developing sector of orchard production in Poland. $57 \%$ of produced raspberries is processed, $14 \%$ as eaten fresh, and $29 \%$ intended for export. The aim of this study was to detect pesticide residues in the berries originating from the region of south-eastern Poland in 2009-2012. A total of 82 samples were tested using the gas chromatography technique (GC/ECD/NPD - gas chromatography with electron capture and nitrogen phosphorus detection). The control programme included the detection of 129 active substances in 2009, 136 in 2010, 151 in 2011 and 165 active substances in 2012. The results were compared with the maximum residue limits (MRLs). 50\% of samples tested contained pesticide residues, and exceeding of MRLs values was stated in 12 samples. These were the residues of esfenvalerate and procymidone, not allowed to apply in raspberry crops. The fungicides were the most frequently detected in the all analysed samples among the other: pyrimethanil (33\% of samples), procymidone (19.5\%), cyprodinil $(13.4 \%)$ and iprodione (12.2\%). The results on pesticides detected in the material tested were comparable with the ones given by other authors.
\end{abstract}

Key words: pesticide residues, raspberries, MRL

\section{Streszczenie}

Maliny należą do szerokiej grupy roślin jagodowych, których uprawa jest ważną i dynamicznie rozwijającą się w Polsce gałęzią produkcji sadowniczej. Do przetwórstwa trafia 57\% malin, do spożycia w stanie świeżym - 14\%, a na eksport 29\%. Celem pracy była ocena występowania pozostałości środków ochrony roślin (ś.o.r.) w malinach pochodzących z rejonu południowo-wschodniej Polski w latach 2009-2012. Przebadano 82 próbki malin. Do analizy pozostałości wykorzystano technikę chromatografii gazowej (GC/ECD/NPD - gas chromatography with electron capture and nitrogen phosphorus detection - chromatografia gazowa połączona z detekcją wychwytu elektronów i azotowo-fosforową). Program kontroli obejmował oznaczenie 129 substancji czynnych (s.cz.) w 2009 r., 136 s.cz. w 2010 r., 151 s.cz. w 2011 r. i 165 s.cz. w 2012 r. Uzyskane wyniki porównywano z najwyższymi dopuszczalnymi poziomami pozostałości (NDP). 50\% przebadanych próbek zawierało pozostałości ś.o.r., a przekroczenia NDP zanotowano w 12 próbkach i dotyczyły one esfenwaleratu oraz procymidonu, który jest niedozwolony. Najczęściej wykrywaną grupą ś.o.r. były fungicydy, a wśród nich pirymetanil (33\% analizowanych próbek), procymidon (19,5\%), cyprodynil (13,4\%) i iprodion (12,2\%). Uzyskane wyniki badań korelują z danymi podawanymi przez innych autorów.

Słowa kluczowe: pozostałości pestycydów, maliny, NDP

Instytut Ochrony Roślin - Państwowy Instytut Badawczy

Terenowa Stacja Doświadczalna

Langiewicza 28, 35-101 Rzeszów

a.matyaszek@iorpib.poznan.pl 


\section{Wstęp / Introduction}

Maliny należą do szerokiej grupy roślin jagodowych. Uprawa tych roślin jest ważną i dynamicznie rozwijającą się w Polsce gałęzią produkcji sadowniczej. Obok ciągle licznych, drobnych nasadzeń, powstają wielohektarowe plantacje (Łabanowska i Gajek 2004). Polska jest liderem w produkcji owoców jagodowych w Europie. Powierzchnia uprawy malin w Polsce wynosi 29,6 tys. ha. Do przetwórstwa trafia $57 \%$ malin, do spożycia w stanie świeżym - 14\%, a na eksport 29\% (Czerwiński 2009; GUS 2012b). Produkcję tych owoców (biorąc pod uwagę dobrze zapowiadający się zbiór malin jesiennych), szacuje się w roku 2012 na około 123 tys. ton, tj. o ponad 4\% więcej od bardzo wysokich zbiorów roku 2011 (GUS 2012c). Średnie miesięczne spożycie owoców jagodowych na 1 osobę w gospodarstwach domowych wynosi $0,39 \mathrm{~kg}$ (GUS 2012a).

Zamieszczone powyżej dane wskazują, iż maliny są uprawiane $\mathrm{w}$ Polsce na dużą skalę i następnie konsumowane w postaci świeżej lub przetworzonej.
Celem pracy była ocena występowania pozostałości środków ochrony roślin (ś.o.r.) w malinach pochodzących z rejonu południowo-wschodniej Polski w latach 2009-2012.

\section{Materiały i metody / Materials and methods}

W latach 2009-2012 w Laboratorium Badania Pozostałości Środków Ochrony Roślin (LBPŚOR) Terenowej Stacji Doświadczalnej w Rzeszowie Instytutu Ochrony Roślin - Państwowego Instytutu Badawczego w Poznaniu poddano analizie 82 próbki malin. Materiał do badań dostarczony został w ramach urzędowej kontroli (współpraca z Ministerstwem Rolnictwa i Rozwoju Wsi oraz Państwową Inspekcją Ochrony Roślin i Nasiennictwa) przez inspektorów Państwowej Inspekcji Ochrony Roślin i Nasiennictwa, a także przez producentów i przetwórców owoców z terenu południowo-wschodniej Polski. Program kontroli obejmował oznaczenie 129 substancji czynnych (s.cz.) w 2009 roku, 136 s.cz. w 2010 roku, 151 s.cz. w 2011 roku i 165 s.cz. ś.o.r. w 2012 roku (tab. 1). Do

Tabela 1. Analizowane substancje czynne

Table 1. Analysed active substances

acetamiprid $(0,05)$, acrinathrin $(0,01)$, aldrin $(0,01)$, alpha-cypermethrin $(0,01)$, azinophos-ethyl $(0,01)$, azinophos-methyl $(0,05)$, beta-cyfluthrin $(0,01)$, bifenthrin $(0,01)$, bromophos-ethyl ${ }^{2}(0,01)$, bromophosmethyl $^{2}(0,01)$, bromopropylate $(0,01)$, buprofezin $(0,01)$, cadusafos ${ }^{3}(0,01)$, carbaryl $(0,02)$, carbofuran $(0,02)$, chlorfenvinphos $(0,01)$, chlorpyrifos $(0,01)$, chlorpyrifos-methyl $(0,01)$, cyfluthrin $(0,01)$, cypermethrin $(0,01)$, p,p'- DDD $(0,01)$, p,p'- DDE $(0,01)$, o,p'- DDT $(0,01)$, p,p'- DDT $(0,01)$, deltamethrin $(0,02)$, diazinon $(0,01)$, dichlorvos $(0,01)$, dicofol $(0,01)$, dieldrin $(0,006)$, dimethoate $(0,02)$, endosulfan alfa $(0,01)$, endosulfan beta $(0,01)$, endosulfan $\mathrm{SO}_{2}(0,01)$, endrin $(0,01)$, esfenvalerate $(0,01)$, ethion $(0,01)$, ethoprophos ${ }^{1}(0,01)$, fenazaquin $(0,01)$, fenchlorphos ${ }^{2}(0,01)$, fenitrothion $(0,01)$, fenpropathrin $(0,01)$, fenthion ${ }^{2}(0,01)$, fenvalerate $(0,01)$, fipronil $(0,005)$, formothion $(0,01)$, HCB $(0,01), \alpha-\mathrm{HCH}(0,01), \beta-\mathrm{HCH}(0,01), \gamma-\mathrm{HCH}$ (lindane) $(0,01)$, heptachlor $(0,01)$, heptachlor-endoepoxide $(0,003)$, heptachlor-exo-epoxide $(0,001)$, heptenophos $(0,01)$, hexythiazox $(0,01)$, indoxacarb $(0,02)$, isofenphos $(0,01)$, isofenphos-methyl ${ }^{1}(0,01)$, lambda-cyhalothrin $(0,01)$, malathion $(0,01)$, mecarbam $(0,01)$, methacrifos ${ }^{1}(0,01)$, methidathion $(0,01)$, methoxychlor $(0,01)$, parathion-ethyl $(0,01)$, parathion-methyl $(0,01)$, permethrin $(0,02)$, phosalone $(0,01)$, phosmet $^{1}(0,01)$, pirimicarb $(0,01)$, pirimiphos-ethyl $^{2}(0,01)$ pirimiphos-methyl $(0,01)$, profenofos ${ }^{1}(0,01)$, propoxur $(0,05)$, pyridaben $(0,02)$, pyriproxyfen $(0,02)$, quinalphos $(0,01)$, tebufenpyrad $(0,01)$, teflubenzuron ${ }^{3}(0,01)$, tetrachlorvinphos ${ }^{2}$ $(0,01)$, tetradifon $(0,01)$, triazophos $(0,01)$, zeta-cypermethrin $(0,01)$

Insektycydy

Insecticides

azaconazole $^{2}(0,01)$, azoxystrobin $(0,01)$, benalaxyl $(0,05)$, bitertanol $(0,05)$, boscalid $(0,01)$, bromuconazole $(0,01)$, bupirimate $(0,01)$, captan $(0,02)$, chlorothalonil $(0,01)$, cyproconazole $(0,01)$, cyprodinil $(0,02)$, dichlofluanid $(0,01)$, dicloran $(0,01)$, difenoconazole $(0,01)$, dimethomorph $(0,01)$, dimoxystrobin $^{2}(0,01)$, diniconazole $(0,01)$, diphenylamine $(0,05)$, epoxiconazole $(0,01)$, fenarimol $(0,01)$, fenbuconazole $(0,02)$, fenhexamid $(0,05)$, fenpropimorph $(0,02)$, fludioxonil $(0,01)$, Fungicydy Fungicides fluquinconazole $(0,01)$, flusilazole $(0,01)$, flutriafol ${ }^{2}(0,02)$, folpet $(0,01)$, hexaconazole ${ }^{3}(0,01)$, imazalil $(0,02)$, imibenconazole ${ }^{2}(0,01)$, iprodione $(0,02)$, krezoxim-methyl $(0,01)$, mepanipyrim $(0,01)$, metalaxyl $(0,01)$, metconazole $^{3}(0,02)$, myclobutanil $(0,01)$, oxadixyl $(0,01)$, penconazole $(0,01)$, pencycuron $^{3}(0,05)$, picoxystrobin ${ }^{1}(0,01)$, prochloraz ${ }^{1}(0,01)$, procymidone $(0,01)$, propiconazole $(0,01)$, pyrazophos ${ }^{2}(0,01)$, pyrimethanil $(0,01)$, quinoxyfen $(0,01)$, quintozene $(0,01)$, tebuconazole $(0,02)$, tecnazene $(0,01)$, tetraconazole $(0,01)$, tolclofos-methyl $(0,01)$, tolylfluanid $(0,01)$, triadimefon $(0,01)$, triadimenol $(0,01)$, trifloxystrobin $(0,01)$, vinclozolin $(0,01)$, zoxamide $^{3}(0,01)$

acetochlor $^{2}(0,01)$, atrazine $(0,01)$, bromacil $^{3}(0,01)$, chlorpropham $(0,01)$, cyanazine ${ }^{3}(0,01)$, cyprazine $^{3}$ $(0,01)$, diflufenican $^{3}(0,01)$, flurochloridone ${ }^{3}(0,01)$, lenacil $(0,05)$, linuron $(0,05)$, metribuzin $(0,01)$,

Herbicydy Herbicides metazachlor $^{2}(0,01)$, napropamide $(0,05)$, nitrofen $(0,01)$, oxyfluorfen ${ }^{3}(0,01)$, pendimethalin $(0,02)$, prometryn $(0,01)$, propachlor $(0,01)$, propaquizafop ${ }^{3}(0,05)$, propazine ${ }^{3}(0,01)$, propham $(0,02)$, propyzamide $(0,01)$, simazine $(0,01)$, trifluralin $(0,01)$

\begin{tabular}{|c|c|}
\hline $\begin{array}{l}\text { Regulatory wzrostu } \\
\text { Growth retardant }\end{array}$ & paclobutrazol $^{2}(0,01)$ \\
\hline $\begin{array}{l}{ }^{1} \text { substancje włączone d } \\
{ }^{2} \text { substancje włączone d } \\
{ }^{3} \text { substancje włączone d } \\
\text { W nawiasach podano g. }\end{array}$ & $\begin{array}{l}\text { adań od } 2010 \text { roku - substances included in the scope of the study from } 2010 \\
\text { adań od } 2011 \text { roku - substances included in the scope of the study from } 2011 \\
\text { adań od } 2012 \text { roku - substances included in the scope of the study from } 2012 \\
\text { aczalności w } \mathrm{mg} / \mathrm{kg} \text { - The limits of determination were given in brackets in mg }\end{array}$ \\
\hline
\end{tabular}


analizy pozostałości ś.o.r. stosowano akredytowaną, według PN-EN ISO/IEC 17025 (2005), metodę analityczną GC/ECD/NPD (gas chromatography with electron capture and nitrogen phosphorus detection - chromatografia gazowa połączona $\mathrm{z}$ detekcją wychwytu elektronów i azotowo-fosforowa) umożliwiającą jednoczesne wykrycie wielu związków o zróżnicowanej budowie chemicznej.

\section{Oznaczanie pozostałości środków ochrony roślin metodą chromatografii gazowej}

Próbkę analityczną (100 g) homogenizowano z acetonem i sączono pod próżnią przez sączek umieszczony na lejku Büchnera. Do dalszej analizy pobierano 1/5 objętości uzyskanego przesączu i umieszczano w rozdzielaczu zawierającym $2,5 \%$ siarczan (VI) sodu. Uzyskany przesącz ekstrahowano trzykrotnie dichlorometanem. Połączone ekstrakty odparowywano do sucha za pomocą wyparki obrotowej Rotavapor-R firmy Büchi w temperaturze poniżej $40^{\circ} \mathrm{C}$, a następnie przenoszono eterem naftowym do kolby miarowej o pojemności $10 \mathrm{ml}$. Uzyskane ekstrakty oczyszczano na kolumnie florisilowej. Pestycydy eluowano mieszaniną eter dietylowy:eter naftowy 3:7 (v/v), a następnie mieszaniną eter naftowy:aceton 7:3 (v/v). Eluaty odparowywano do sucha na wyparce obrotowej. Suchą pozostałość przenoszono eterem naftowym ilościowo do kolbek miarowych o pojemności $10 \mathrm{ml}$ i uzupełniano zawartość eterem naftowym.

Oczyszczone ekstrakty analizowano na chromatografie gazowym Agilent 6890 wyposażonym w detektory EC i NP (kolumna DB-1701; program temperatur: temperatura początkowa $100^{\circ} \mathrm{C} \rightarrow 20^{\circ} \mathrm{C} / \mathrm{min} \rightarrow 180^{\circ} \mathrm{C}-4 \mathrm{~min} \rightarrow$ $20^{\circ} \mathrm{C} / \mathrm{min} \rightarrow 220^{\circ} \mathrm{C}-5 \mathrm{~min} \rightarrow 20^{\circ} \mathrm{C} / \mathrm{min} \rightarrow 260^{\circ} \mathrm{C}-43 \mathrm{~min}$; łączny czas analizy 60 minut). Wyniki potwierdzano na chromatografie Hewlett Packard 7890 wyposażonym w detektory EC i NP (kolumna HP-5MS; program temperatur: temperatura początkowa $100^{\circ} \mathrm{C} \rightarrow 10^{\circ} \mathrm{C} / \mathrm{min} \rightarrow 180^{\circ} \mathrm{C}$ $-4 \mathrm{~min} \rightarrow 3^{\circ} \mathrm{C} / \mathrm{min} \rightarrow 220^{\circ} \mathrm{C}-15 \mathrm{~min} \rightarrow 10^{\circ} \mathrm{C} / \mathrm{min} \rightarrow$ $260^{\circ} \mathrm{C}-11 \mathrm{~min}$; łączny czas analizy 55 minut) $\mathrm{w}$ zakresie liniowości ich wskazań (Grzegorzak i wsp. 2012).

Uzyskane wyniki porównywano z obowiązującymi w Polsce najwyższymi dopuszczalnymi poziomami pozostałości (NDP) określonymi w Rozporządzeniu 396/2005 Parlamentu Europejskiego i Rady (Rozporządzenie 2005).

\section{Wyniki i dyskusja / Results and discussion}

Spośród przebadanych 82 próbek malin w 50\% (41 próbek) wykryto pozostałości ś.o.r. W 29 próbkach (35,4\%) stężenie oznaczonych pozostałości było niższe od NDP. Przekroczenia NDP zanotowano w 12 próbkach $(14,6 \%)$ i dotyczyły one substancji: esfenwalerat i procymidon (rys. 1).

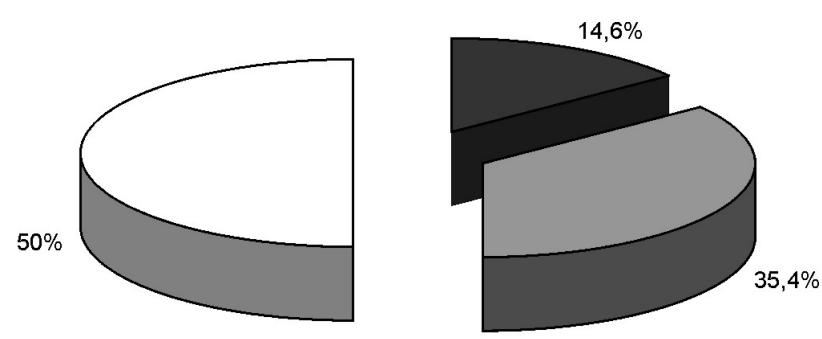

- Próbki z pozostałościami > NDP - Samples with pesticide residues $>$ MRLs

$\square$ Próbki z pozostałościami < NDP - Samples with pesticide residues < MRLs

$\square$ Próbki z pozostałościami < granicy oznaczalności

Samples with pesticide residues $<$ limit of quantification

Rys. 1. Pozostałości ś.o.r. w malinach, w latach 2009-2012

Fig. 1. Pesticide residues in raspberries, in 2009-2012

Tabela 2. Występowanie pozostałości ś.o.r. w malinach, w latach 2009-2012

Table 2. Occurrence of pesticide residues in raspberries, in 2009-2012

\begin{tabular}{|c|c|c|c|c|c|c|}
\hline \multirow{2}{*}{$\begin{array}{l}\text { Uprawa } \\
\text { Crop }\end{array}$} & \multirow{2}{*}{$\begin{array}{c}\text { Liczba badanych próbek } \\
\text { Number } \\
\text { of analysed samples }\end{array}$} & \multirow{2}{*}{$\begin{array}{l}\text { Substancja czynna } \\
\text { Active substance }\end{array}$} & \multicolumn{2}{|c|}{$\begin{array}{c}\text { Próbki } \\
\text { z pozostałościami } \\
\text { Samples with residues }\end{array}$} & \multirow{2}{*}{\begin{tabular}{|c}
$\begin{array}{c}\text { Zakres wykrywanych } \\
\text { pozostałości } \\
\text { Range of detected residues }\end{array}$ \\
$\begin{array}{c}\min -\max \\
{[\mathrm{mg} / \mathrm{kg}]}\end{array}$
\end{tabular}} & \multirow{2}{*}{$\begin{array}{c}\text { NDP } \\
\text { MRL } \\
{[\mathrm{mg} / \mathrm{kg}]}\end{array}$} \\
\hline & & & $\begin{array}{l}\text { liczba } \\
\text { number }\end{array}$ & {$[\%]$} & & \\
\hline $\begin{array}{l}\text { Malina } \\
\text { Raspberry }\end{array}$ & 82 & $\begin{array}{c}\text { boscalid } \\
\text { captan }^{2} \\
\text { chlorpyrifos } \\
\text { lambda-cyhalothrin } \\
\text { cypermethrin } \\
\text { cyprodinil } \\
\text { esfenvalerate } \\
\text { fenhexamid } \\
\text { fludioxonil }^{3} \\
\text { folpet }^{2} \\
\text { iprodione } \\
\text { pirimethanil } \\
\text { pirimicarb } \\
\text { procymidone }\end{array}$ & $\begin{array}{c}1 \\
1 \\
3 \\
1 \\
3 \\
11 \\
1 \\
1 \\
8 \\
1 \\
10 \\
27 \\
2 \\
16\end{array}$ & $\begin{array}{c}1,2 \\
1,2 \\
3,7 \\
1,2 \\
3,7 \\
13,4 \\
1,2 \\
1,2 \\
9,8 \\
1,2 \\
12,2 \\
33 \\
2,4 \\
19,5\end{array}$ & $\begin{array}{c}0,63 \\
0,02 \\
0,01-0,11 \\
0,01 \\
0,03-0,08 \\
0,01-0,36 \\
0,04 \\
0,18 \\
0,03-0,3 \\
0,04 \\
0,05-0,75 \\
0,02-0,85 \\
0,06-0,09 \\
0,01-1,68\end{array}$ & $\begin{array}{c}10 \\
3 \\
0,5 \\
0,2 \\
0,5 \\
10 \\
0,02 \\
10 \\
5 \\
3 \\
10 \\
10 \\
2 \\
0,02\end{array}$ \\
\hline
\end{tabular}

NDP - najwyższe dopuszczalne poziomy pozostałości - MRL - maximum residue limits

${ }^{1}$ substancja, której stosowanie jest zabronione - application of the substance was forbidden

${ }^{2}$ substancja, której stosowanie nie jest zalecane w danej uprawie - application of the substance was not recommended for that crop

${ }^{3}$ substancja, której pozostałość przekroczyła najwyższy dopuszczalny poziom (NDP) - the substance which residue level exceeded the Maximum Residue Limit (MRL) 


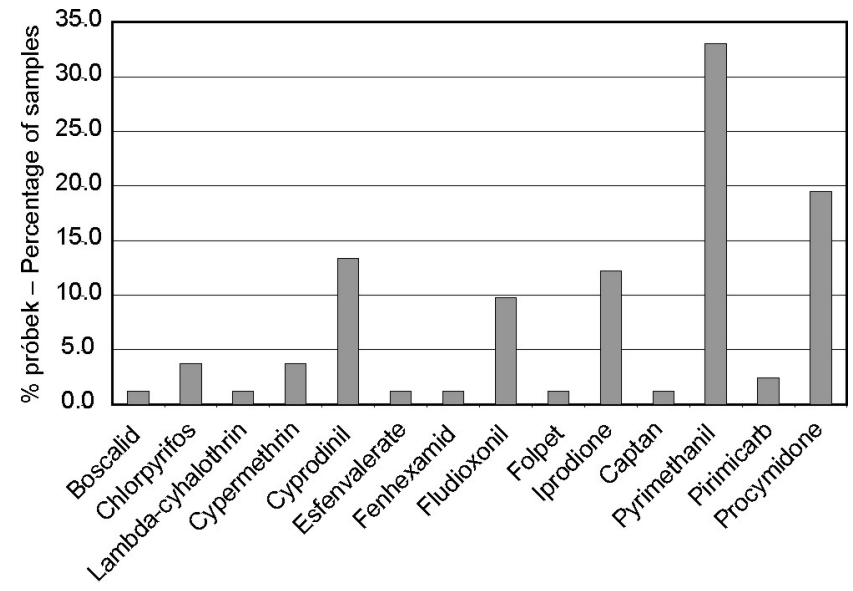

Rys. 2. Częstotliwość występowania pozostałości ś.o.r. w malinach, w latach 2009-2012

Fig. 2. Frequency of pesticide residues detected in raspberries, in 2009-2012

W omawianym okresie badawczym w próbkach poszukiwano od 129 do 165 s.cz. ś.o.r. Wykryto 14, które należały do grupy fungicydów (9 s.cz.) i insektycydów (6 s.cz.). Do najczęściej występujących należały s.cz. z grupy fugicydów: pirymetanil $(33 \%$ analizowanych próbek), procymidon (19,5\%), cyprodynil $(13,4 \%)$ i iprodion $(12,2 \%)$ (rys. 2). Najwyższe wykryte stężenia dotyczyły także fungicydów: procymidon - $1,68 \mathrm{mg} / \mathrm{kg}$, pirymetanil - 0,85 $\mathrm{mg} / \mathrm{kg}$, iprodion - 0,75 $\mathrm{mg} / \mathrm{kg}$. Szczegółowe dane występowania pozostałości ś.o.r. w malinach przedstawiono $\mathrm{w}$ tabeli 2 .

W trakcie badań wykonanych w latach 2009-2012 w LBPŚOR w Rzeszowie w 2 próbkach wykryto pozostałości s.cz. ś.o.r. niezalecanych do ochrony malin, tj. folpet i kaptan. Wykryto także s.cz., której stosowanie jest zabronione od 2008 roku, tj. procymidon (Rozporządzenie 2005, 2008). Substancję tą wykryto aż w 16 próbkach. W trakcie badań stwierdzono obecność pozostałości jednoi wielokrotnych. W 16 próbkach malin wykryto obecność jednej pozostałości ś.o.r., w 13 próbkach - dwie pozostałości, w 6 próbkach trzy pozostałości, w 5 próbkach znajdowały się cztery pozostałości, natomiast w jednej próbce wykryto pozostałości aż sześciu s.cz. tj.: procymidonu, pirymikarbu, pirymetanilu, iprodionu, cyprodinilu i chloropiryfosu (rys. 3).

Uzyskane wyniki korelują $z$ danymi podawanymi przez innych autorów: duży odsetek próbek malin $\mathrm{z}$ pozostałościami ś.o.r. wystąpił także w innych rejonach Polski, a najczęściej wykrywaną grupą substancji były również fungicydy. Częstotliwość wykrywanych s.cz. również była na podobnym poziomie, m.in. pirymetanil, iprodion, cyprodinil (Sadło i wsp. 2007; Łozowicka i wsp. 2010, 2012; Nowacka i wsp. 2011, 2012).

Maliny, tak jak i inne rośliny sadownicze, atakowane są przez liczne choroby i szkodniki, które powoduja straty w plonie, obniżają jakość owoców oraz osłabiają wzrost roślin (Rusnak 2011).

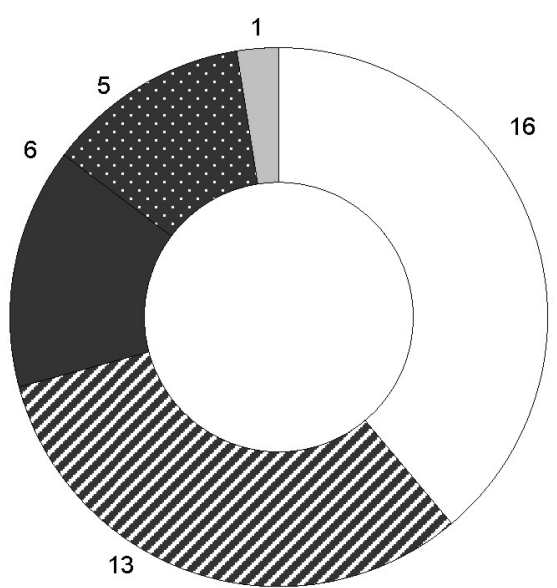

$\square$ Próbki z 1 pozostałością ś.o.r. - Samples with 1 pesticide residue

• Próbki z 2 pozostałościami ś.o.r. - Samples with 2 pesticide residues

- Próbki z 3 pozostałościami ś.o.r. - Samples with 3 pesticide residues

- Próbki z 4 pozostałościami ś.o.r. - Samples with 4 pesticide residues

ㅁ Próbki z 6 pozostałościami ś.o.r. - Samples with 6 pesticide residues

Fig. 3. Multipozostałości w próbkach malin, w latach 2009-2012

Fig. 3. Multiresidues in raspberry samples, in 2009-2012

\section{Wnioski / Conclusions}

1. W 50\% przebadanych próbkach malin stwierdzono występowanie pozostałości ś.o.r. Najczęściej wykrywaną grupa związków były fungicydy.

2. W 12 próbkach $(14,6 \%)$ wykryto przekroczenia NDP, w 16 próbkach stwierdzono substancję, która jest zabroniona od 2008 roku - procymidon, i dodatkowo w 2 próbkach stwierdzono pozostałości ś.o.r, które są niezalecane do ochrony malin (folpet i kaptan).

3. Nieprawidłowości związane ze stosowaniem środków ochrony roślin w większej liczbie przypadków dotyczyły zastosowania substancji niezalecanych do ochrony malin, niż przypadków, gdzie stwierdzono występowanie przekroczeń NDP.

\section{Literatura / References}

Czerwiński H. 2009. Przyszłość owoców jagodowych w Polsce. Sad Nowoczesny 2/2009, 70 ss.

Grzegorzak M., Szpyrka E., Słowik-Borowiec M., Kurdziel A., Matyaszek A., Rupar J. 2012. Potential risk to consumer related with occurrence of pesticide residues in early vegetables. Ecol. Chem. Eng. A, 19 (3): 239-248. DOI: 10.2428/ecea.2012.19(03)025.

GUS 2012a. Budżety gospodarstw domowych w $2011 \mathrm{r}$. Informacje i opracowania statystyczne. Warszawa, $293 \mathrm{ss}$.

GUS 2012b. Rocznik Statystyki Międzynarodowej 2012. Warszawa, 614 ss. 
GUS 2012c. Wstępny szacunek głównych ziemiopłodów rolnych i ogrodniczych w 2012 r. Informacja sygnalna. Wyniki wstępne. Warszawa, 18 ss.

Łabanowska B., Gajek D. 2004. Szkodniki krzewów owocowych. Plantpress Sp. z o.o., Kraków, 172 ss.

Łozowicka B., Jankowska M., Rutkowska E., Kaczyński P. 2010. Pozostałości fungicydów i insektycydów w owocach jagodowych i sokach $z$ owoców jagodowych. [Fungicide and insecticide residues in berry fruits and fruit juices]. Prog. Plant Prot./Post. Ochr. Roślin 50 (3): 1445-1451.

Łozowicka B., Kaczyński P., Jankowska M., Rutkowska E., Rynko I. 2012. Pesticide residues in raspberries (Rubus idaeus L.) and dietary risk assessment. Food Additives and Contaminants: Part B Surveillance 5 (3): 165-171.

Nowacka A., Gnusowski B., Walorczyk S., Drożdżyński D., Raczkowski M., Hołodyńska A., Frąckowiak D., Wójcik A., Ziółkowski A., Rzeszutko U., Domańska I., Jurys J., Łozowicka B., Kaczyński P., Rutkowska E., Jankowska M., Hrynko I., Szpyrka E., Rupar J., Rogozińska K., Kurdziel A., Słowik-Borowiec M., Michel M., Kuźmenko A., Szala J. 2011. Pozostałości środków ochrony roślin w płodach rolnych (rok 2010). [Pesticide residues in polish crops (2010)]. Prog. Plant Prot./Post. Ochr. Roślin 51 (4): $1723-1738$.

Nowacka A., Gusowski B., Walorczyk S., Drożdżyński D., Raczkowski M., Hołodyńska A., Frąckowiak D., Wójcik A., Ziółkowski A., Przewoźniak M., Swoboda W., Rzeszutko U., Domańska I., Jurys J., Łozowicka B., Kaczyński P., Rutkowska E., Jankowska M., Rynko I., Szpyrka E., Rupar J., Rogozińska K., Kurdziel A., Słowik-Borowiec M., Szala J., Szponik M., Michel M. 2012. Pozostałości środków ochrony roślin w płodach rolnych (rok 2011). [Pesticide residues in Polish crops (2011)]. Prog. Plant Prot./Post. Ochr. Roślin 52 (4): 1160-1116.

PN-EN ISO/IEC 17025. 2005. Ogólne wymagania dotyczące kompetencji laboratoriów badawczych i wzorcujących, 42 ss.

Rozporządzenie 396/2005 Parlamentu Europejskiego i Rady z dnia 23 lutego 2005 r. w sprawie najwyższych dopuszczalnych poziomów pozostałości pestycydów w żywności i paszy pochodzenia roślinnego i zwierzęcego oraz na ich powierzchni zmieniające dyrektywę Rady 91/414/EWG. (Dz. Urz. UE, L 70, 16.03.2008 r., z późn. zm.).

Rozporządzenie Ministra Zdrowia i Rozwoju Wsi z dnia 2 grudnia 2008 r. zmieniające rozporządzenie w sprawie wykazu substancji aktywnych, których stosowanie w środkach ochrony roślin jest zabronione (Dz. U. z 2008 r. Nr 218, poz. 1398).

Rusnak J. 2011. Ochrona malin przed chorobami i szkodnikami. Małopolski Ośrodek Doradztwa Rolniczego, Karniowice, 24 ss.

Sadło S., Szpyrka E., Rogozińska K., Rupar J., Kuźmenko A. 2007. Występowanie pozostałości pestycydów w malinach w latach 2000-2005. Rocz. PZH 58 (3): 509-513. 